Para enlazar con este artículo / To link to this article:

https://doi.org/10.6035/MonTI.2020.12.09

Para citar este artículo / To cite this article:

Carlucci, Laura \& Claudia Seibel. (2020) "El discurso especializado en el museo inclusivo: lectura fácil versus audiodescripción." En: Richart-Marset, Mabel \& Francesca Calamita (eds.) 2020. Traducción y Accesibilidad en los medios de comunicación: de la teoría a la práctica / Translation and Media Accessibility: from Theory to Practice. MonTI 12, pp. 262-294.

\title{
EL DISCURSO ESPECIALIZADO EN EL MUSEO INCLUSIVO: LECTURA FÁCIL VERSUS AUDIODESCRIPCIÓN
}

\author{
LAURA CARLUCCI \\ carlucci@ugr.es \\ Universidad de Granada \\ Claudia Seibel \\ cseibel@ugr.es \\ Universidad de Granada
}

\section{Resumen $^{1}$}

En este estudio se ofrecen algunos resultados de un proyecto de investigación centrado en el museo como lugar de acceso al ocio y la cultura para usuarios con discapacidad sensorial y cognitiva, describiendo algunos de los principales problemas terminológicos asociados a las cuestiones relativas a dos modalidades de traducción accesible museística: Audiodescripción y Lectura fácil. Nuestra interpretación de los resultados permitirá avanzar en la búsqueda de indicadores de calidad para los recursos accesibles museísticos, que representan el producto de un complejo proceso de traducción intersemiótica, intralingüística y/o interlingüística de la obra artística.

Palabras clave: Discurso especializado; Museo inclusivo; Traducción accesible; Lectura fácil; Audiodescripción.

1. Esta investigación se ha llevado a cabo en el marco del Proyecto I+D+i OPERA [Acceso al ocio y a la cultura. Plataforma de difusión y evaluación de recursos audiovisuales accesibles (FFI2015-65934-R)], financiado por el Ministerio de Economía, Industria y Competitividad. 


\begin{abstract}
"The specialized discourse in the inclusive museum: Easy Reading versus Audio description"

In this paper we present the results of a research work centered on the museum as a place of access to leisure and culture for everyone, describing some of the main terminological problems associated with the questions dealing with two modalities of accessible translation in museums: audio description and easy reading. Our interpretation of the results will allow us to advance in the search for quality indicators for accessible museum resources, which are the product of a complex process of translation - at once intersemiotic, intralinguistic and/or interlinguistic - of the work of art.
\end{abstract}

Keywords: Specialized discourse; Inclusive museum; Accessible translation; Easy reading; Audio description.

\title{
1. Introducción
}

Las ideas y propuestas que presentamos en este artículo son reflejo de un proyecto de colaboración entre el equipo de investigación TRACCE (Traducción y accesibilidad) de la Universidad de Granada y el Museo Memoria de Andalucía, cuyos novedosos recursos museográficos multimedia interactivos lo convierten en uno de los museos más modernos e innovadores de España. El punto de partida de esta colaboración es el Proyecto CITRA: Cultura Inclusiva a través de la Traducción, que se enmarca dentro de los estudios más recientes sobre la Traducción accesible y el acceso al conocimiento de colectivos con discapacidad visual, auditiva y cognitiva. En este estudio nos decantamos por analizar dos modalidades de Traducción accesible, la Audiodescripción para ciegos y la Lectura Fácil (en adelante, AD y LF), para explicar los principales procesos de estos tipos de traducción accesible, a través del análisis del discurso especializado, la competencia textual y la escritural (Carlucci 2018). Nuestra interpretación de algunos de los resultados del proyecto permitirá concebir próximas investigaciones y experiencias que permitan avanzar en las teorías y la concepción de indicadores de calidad para los recursos accesibles museísticos, que representan el producto de un complejo proceso de traducción intersemiótica, intralingüística y/o interlingüística de la obra artística.

En este sentido, queremos insistir en el hecho de que los estándares de calidad de los recursos accesibles son fundamentales para alcanzar la plena 
inclusión de todos los colectivos de visitantes del museo. Estos estándares de calidad deben tener en cuenta necesariamente factores diversos, ante todo la valoración del producto por parte de los usuarios, para seguir analizando y mejorando los recursos accesibles, considerando que la información en el ámbito museístico tiene lugar en contextos muy distintos y variados, en los que los visitantes presentan lenguas y culturas distintas, diferentes profesiones, necesidades y grados de conocimiento previo, por lo que conviven necesariamente diversos tipos de discursos. El proceso de creación del guion audiodescriptivo o la adaptación en LF de un objeto museístico pertenecen a un determinado género textual y poseen un lenguaje propio, a menudo especializado; el análisis de estos nuevos tipos textuales implica un estudio del conocimiento lingüístico de cada texto, que permita ofrecer datos teóricos y empíricos que contribuyan a mejorar la usabilidad de los recursos accesibles en el ámbito museístico. Para ello, se profundizará en cuestiones relacionadas con el diseño del texto accesible y en aspectos fundamentales como la funcionalidad del mismo.

\section{El museo inclusivo}

Siguiendo el pensamiento de la museología crítica, el museo ha superado el paradigma comunicativo de la nueva museología para convertirse en un museo de participación cultural e inclusión social. Esta corriente busca formar a una ciudadanía más dispuesta a expresar su opinión, no sólo consumista, en un "lugar idóneo para el diálogo y también como razón del debate" (Flores Crespo 2006: 232). La definición de museo proporcionada por el ICOM (Consejo Internacional de Museos) constituye el punto de partida para la visión que tenemos de los museos hoy en día. A partir de esta definición, surge la nueva visión del papel social del museo:

Un museo es una institución permanente sin fines de lucro al servicio de la sociedad y de su desarrollo, abierta al público, que adquiere, conserva, investiga, transmite y expone el patrimonio tangible e intangible de la humanidad y de su entorno para la educación, el estudio y el deleite (ICOM Estatutos. Art. 3, 1, p. 3).

Paralelamente a este proceso de democratización del museo, los movimientos sociales y la investigación en torno a la discapacidad en las últimas décadas 
han promovido un cambio fundamental en la museología. En este sentido, la discapacidad ya no deriva directa y exclusivamente de la deficiencia física de la persona, sino que es consecuencia de las barreras impuestas por una sociedad que no se ha diseñado pensando en la diversidad humana (Barnes \& Mercer 2010: 30).

El proyecto en el que se basa este artículo surgió a raíz del nuevo concepto de museo y objeto museístico que se asienta ya no en la exposición como razón de ser del museo, sino en el visitante/público. El museo accesible tiene que centrarse en la sociedad en su conjunto, es decir, diseñar los contenidos en función de las expectativas y necesidades culturales de los potenciales usuarios del museo. "Han de estar en contacto con el mundo exterior y saber lo que la gente piensa y espera de ellos" (Hernández Hernández 2011: 414). Es fundamental una paulatina implementación en los museos de herramientas que permitan el acceso a personas con discapacidad (física, sensorial, visual o cognitiva), hablantes de lenguas distintas a la del museo, niños o personas mayores con determinadas necesidades, con problemas de visión, de oído, demencia senil, etc. Por el momento, estas reivindicaciones desgraciadamente no han perdido nada de su importancia y actualidad dado que aún muy pocas colecciones son plenamente accesibles.

Para que los museos sean realmente inclusivos habrá que tener en cuenta a todos los potenciales usuarios, con sus diferentes necesidades, deseos y expectativas. Las personas con discapacidad, por tanto, tendrán que participar en el diseño y evaluación de las colecciones y exposiciones de los museos para que estas puedan ser disfrutadas por el mayor número de personas, en vez de recurrir a "soluciones discriminatorias positivas" (Aragall i Clavé et al. 2013: 39). Se trata, por tanto, del diseño de espacios y servicios para todos, "con el mayor grado de independencia posible, aunque en ocasiones haya que usar ayudas técnicas complementarias [...]" (Aragall i Clavé et al. 2013: 39).

El objetivo del museo inclusivo consiste en facilitar que cualquier tipo de visitante tenga la posibilidad de disfrutar del mismo expositivo, pero de diferentes maneras. Una serie de herramientas o modalidades de comunicación accesible, a disposición de los usuarios en función de sus necesidades concretas, ayudará a que estos, a través de diferentes sentidos, puedan disfrutar plenamente de la visita al museo y a facilitar al usuario "el espacio necesario 
para crear sus propios significados, evitando que nadie pueda quedarse fuera" (Hernández Hernández 2011: 414).

\section{El museo como espacio de aprendizaje: el proyecto CITRA}

El Proyecto de Innovación Docente CITRA ha creado un plan de accesibilidad a través de la traducción para la discapacidad visual, auditiva y cognitiva de una selección de expositivos bidimensionales y tridimensionales de la Sala 4 del Museo Memoria de Andalucía, titulada "Arte y cultura". Su principal innovación ha consistido en trascender el aula de traducción tradicional y crear nuevos espacios de aprendizaje, en este caso el museo, que facilitan el trabajo creativo, colaborativo y traductológico, dentro de un proyecto interdisciplinar multilingüe, basado en la teoría socioconstructivista del aprendizaje por competencias y la resolución de problemas (Kiraly 2000).

El plan se ha materializado en la gestión de un proyecto profesional de traducción multimodal accesible con la colaboración de un equipo de ingenieros informáticos del Departamento de Lenguajes y Sistemas Informáticos de la Universidad de Granada que ha desarrollado una plataforma web y una aplicación para dispositivos móviles para Android, que alberga contenidos accesibles en diferentes formatos. Recordemos que se puede hablar de traducción accesible en el caso de que esta elimine la barrera comunicativa que suponga el texto origen (en adelante, TO) para el receptor:

Man kann dann von einer Übersetzung sprechen, wenn der Ausgangstext für die intendierte Zielleserschaft eine Barriere (Sinnesbarriere, Fachbarriere, Fachsprachenbarriere, Kulturbarriere, Kognitionsbarriere, Sprachbarriere oder Medienbarriere) darstellt, die der Zieltext zu überwinden sucht (Maaß 2018: 292).

La autora enumera múltiples barreras: la de los sentidos, de la materia, de los lenguajes especializados, la cultural, cognitiva, del idioma o la multimedia (Maaß 2018). El tipo de barrera puede variar en el mismo texto dependiendo de la situación comunicativa concreta y, sobre todo, del destinatario y sus expectativas en cuanto a la recepción del mensaje. Resulta, por tanto, imprescindible saber a qué grupo de usuarios va dirigido el texto accesible (Maaß 2018: 293). 
A los museos pueden acudir diferentes grupos de visitantes con necesidades muy concretas: personas con deficiencia sensorial, personas que se diferencian en cuanto a sus capacidades cognitivas o grado de conocimiento previo e interés, usuarios que piden una visita más rápida y superficial o, por el contrario, una visita más profunda, niños así como hablantes de otras lenguas distintas al español, entre otros. Atendiendo a las necesidades de estos colectivos, gracias al proyecto CITRA se crearon signoguías, audioguías, adaptaciones a LF, así como las traducciones de todo el material en otras lenguas como italiano, francés, alemán o portugués.

En relación con la simulación profesional de encargos de traducción, es importante destacar la estrategia de profesionalización que se llevó a cabo, que incluyó todas las fases del proceso, así como el trato con usuarios con discapacidad y con capacidades y habilidades específicas, de cara a incluir nuevas materias tanto en el Grado en Traducción e Interpretación como en el Máster en Traducción Profesional de la Universidad de Granada. Esta estrategia de profesionalización ha generado una colaboración interdisciplinar entre los miembros del proyecto y diferentes empresas, asociaciones y entidades, así como el trabajo colaborativo con estudiantes de diferentes departamentos y grados. Consideramos que ha sido un logro situar al estudiante en el centro de la cadena de producción del proyecto; verse evaluados por las propias empresas del sector, así como por los usuarios de sus recursos, supone para los alumnos un estímulo añadido e influye positivamente en su grado de motivación e implicación.

Se trata, a nuestro entender, de un reto para la innovación en la teoría y la didáctica de la traducción profesional. De hecho, no nos consta que se aplique la accesibilidad en museos como recurso didáctico o que se utilice un museo en plena actividad como espacio de aprendizaje y fuente temática de los materiales docentes para el autoaprendizaje de las complejidades del proceso traductor en ámbito profesional.

\section{Metodología}

En cuanto a la metodología, para alcanzar el objetivo de esta investigación se analizarán algunos recursos accesibles museísticos, concretamente audiodescripciones y textos en LF, elaborados por los investigadores del grupo TRACCE, en colaboración con profesores y alumnos de Grado y Posgrado de la Facultad de Traducción e Interpretación de la Universidad de Granada. Este 
estudio descriptivo comparativo permitirá reunir datos valiosos que servirán para perfilar las estrategias o técnicas de traducción ${ }^{2}$ adoptadas e individuar cuáles han sido las predominantes a la hora de abordar la AD y LF de textos especializados. Nos ceñiremos al análisis de términos pertenecientes al lenguaje especializado, atendiendo a las estrategias que se emplearon en estas dos modalidades de traducción intersemiótica. Mediante esta muestra podremos comprobar y evaluar el grado de precisión y la cantidad de información destinada al visitante con discapacidad visual o cognitiva, para verificar si ambas modalidades de traducción accesible difieren entre ellas con respecto a la cantidad de información especializada que proporcionan. Para ello, seguiremos las pautas y directrices de autores como Maaß (2018) y García Muñoz (2012 y 2014) para la redacción de textos en LF, Díaz Cintas (2010), Giansante (2015), Salzhauer Axel et al. (2003), Snyder (2003 y 2010) y Neves (2012) para la AD en contextos museísticos; Heidrich (2016) y Schum (2017), entre otros, para los estudios sobre el discurso especializado.

\section{El discurso especializado en AD y LF}

Según el artículo 1 del Reglamento de los museos de titularidad estatal y del sistema español de museos, estos se definen como "instituciones de carácter permanente que adquieren, conservan, investigan, comunican y exhiben, para fines de estudio, educación y contemplación, conjuntos y colecciones de valor histórico-artístico, científico y técnico o de cualquier otra naturaleza cultural" (BOE 1987: 5). El discurso especializado plasmado en textos científicos y técnicos museísticos muestra determinadas características que habrá que tener en cuenta antes de crear textos audiodescritos o en LF en los que se abarquen temas de un determinado ámbito de especialidad. Ambas

2. En este estudio, utilizamos de forma indistinta los términos técnica de traducción y estrategia de traducción, de acuerdo con Hurtado Albir (2001: 249-250) que define la técnica como "un procedimiento, generalmente verbal, visible en el resultado de la traducción, que se utiliza para conseguir la equivalencia traductora, con cinco características básicas: 1) afectan al resultado de la traducción; 2) se catalogan en comparación con el original; 3) se refieren a microunidades textuales; 4) tienen un carácter discursivo y contextual; 5) son funcionales." (Hurtado Albir 2001: 268), y las estrategias como "mecanismos utilizados por el traductor para resolver los problemas encontrados en el desarrollo del proceso traductor en función de sus necesidades específicas". (Hurtado Albir 2001: 250) 
modalidades de traducción accesible implican, por lo tanto, una mediación intralingüística e intracultural, o bien interlingüística e intercultural, del discurso especializado. En cuanto al léxico del lenguaje de especialidad, destaca por ejemplo el uso frecuente de sustantivos, de la nominalización, de adjetivos muy precisos, abreviaturas, acrónimos y siglas, así como el uso restringido de verbos y adverbios. En el nivel sintáctico, llama la atención el uso de estructuras impersonales, oraciones principales y enunciativas (Schum 2017: 352). Haciendo referencia a Fluck (1996, en Heidrich 2016), Heidrich enumera una serie de propiedades del discurso especializado como los términos, el estilo nominal o la economía expresiva:

Nach Fluck sind die sprachlichen Charakteristika der Fachsprachen die Dominanz der Fachlexik, der Nominalstil, das Fehlen von affektiven und wertenden Wörtern und Wendungen, das Fehlen von dialogischen Partien, die Häufung von Funktionsgefügen und eine Tendenz zur Knappheit im Ausdruck (Heidrich 2016: 86).

Numerosos autores comentan la importancia de una serie de factores que rodean el texto especializado; Stolze considera el grado de abstracción del texto, el nivel de conocimiento del autor así como el supuesto conocimiento previo del receptor como características de textos de especialidad (Stolze 1999: 24). Son precisamente los que determinan el grado de dificultad de un texto. En este sentido, Rodríguez-Tapia (2016) los clasifica en tres grupos: texto especializado, semiespecializado o divulgativo, siendo el primero y tercero dos polos completamente opuestos en cuyo centro se situaría el texto semiespecializado (Rodríguez-Tapia 2016: 988). En el caso de los textos museísticos objeto de este estudio, no se puede aplicar esta clasificación, dado que todos tienen una función divulgativa, independientemente de su grado de especialización. Los expositivos analizados en el marco del proyecto CITRA pertenecen a numerosos ámbitos de especialidad, entre ellos la historia, arquitectura, escultura y pintura, y requieren distintos niveles de dificultad y densidad terminológica. A la hora de elaborar un plan de accesibilidad museístico, es necesario tener en cuenta esta amplitud temática así como el grado de abstracción textual de cada uno de los recursos accesibles.

Volviendo a las barreras que imposibilitan la comunicación, en el caso de personas con discapacidad intelectual nos encontramos con una barrera de tipo cognitivo y, en el caso de muchos inmigrantes, con otra de tipo 
lingüístico: dos barreras totalmente distintas, la primera permanente y la segunda superable con el paso del tiempo (Schum 2017: 357). Aparte de estos dos grupos de posibles receptores de textos redactados en LF, hay que mencionar a las personas sordas prelocutivas y sordociegas, personas con demencia, personas con afasia, con dislexia y otras dificultades lectoras, personas con analfabetismo funcional, niños, inmigrantes y otras personas no nativas de una lengua (Creaccesible 2012, García Muñoz 2012 y 2014).

En cuanto a la estructura textual de textos en LF, el reto reside en transmitir, de forma correcta y poco compleja, realidades que, según el objeto del texto, pueden llegar a ser muy complejas, tal y como lo describe Maaß (2018: 275): "Auf Textebene besteht die Herausforderung darin, dass je nach Textgegenstand teilweise höchst komplexe Gegenstände mit wenig komplexen Mitteln korrekt wiedergegeben werden müssen". En este sentido, no se trataría únicamente de reescribir el texto de forma más sencilla, con el fin de convertirlo en un texto accesible, sino de efectuar una recontextualización completa. El texto museístico se reescribe y se reproduce pensando en el nuevo tipo de usuario y sus necesidades, por lo que ya no sería suficiente la intervención de expertos en un determinado campo de especialidad, sino que se necesitaría contar también con un equipo de traductores que conozcan los nuevos objetivos del texto meta en LF.

En el caso de la $\mathrm{AD}$, el discurso especializado no debe simplificarse, pues el usuario ciego tiene la capacidad de asimilar la misma información que el normovidente. Sin embargo, desde el punto de vista de la competencia escritural, puede ser necesario recurrir a figuras retóricas, sobre todo metáforas y símiles, así como sinónimos. Se pretende, pues, utilizar un lenguaje diferente sin simplificarlo y sin omitir términos, en función del nivel de opacidad del término y del contexto. En el caso de las metáforas y los símiles, se trataría de utilizar imágenes de algún tipo que puedan acercar al usuario a conceptos complejos cuya comprensión les resulta especialmente difícil por el hecho de no poder ver el expositivo al que se refieren. Todos estos recursos lingüísticos se utilizan como glosas intratextuales, breves explicaciones o comentarios que añade el traductor y que se integran en el cuerpo del texto audiodescrito. De este modo, no se pierde la exactitud de la idea; no se trata de parafrasear el discurso especializado, sino de reformularlo y enriquecerlo, construyendo un puente entre el texto del objeto museístico y el visitante con discapacidad visual. 


\subsection{Pautas y criterios de redacción de textos en LF}

La LF como variedad lingüística presenta determinados rasgos diferenciales con relación a la lengua estándar que, resumiendo, se refieren a la reducción del léxico y restricciones importantes en cuanto al nivel sintáctico lo que, a su vez, permite reducir la complejidad y el grado de abstracción de estos textos (Schum 2017: 353). Los cambios léxicos y sintácticos llevados a cabo durante el proceso de traducción pueden llegar a impedir que el TM se reconozca como perteneciente a un determinado género textual. Cuando los autores de textos en LF recurren a determinadas normas de redacción como por ej. la explicitación de vocabulario o glosarios a final de página o texto, así como el uso de una oración por línea, existe el riesgo de que el nuevo texto sea mucho más largo que el TO y que, de esta forma, los lectores pierdan el flujo de lectura dado que tienen que interrumpir la lectura para poder consultar el glosario. En general se puede afirmar que la aplicación de las directrices que se siguen para crear o adaptar textos en LF conlleva importantes cambios en el nuevo texto de forma que a menudo ya no se sabe a qué género textual pertenece. Los textos en LF se llegan a parecerse unos a otros (Maaß 2018: 277). El aspecto de la transparencia del género textual al que pertenece el texto en LF no supone un mayor problema en relación con nuestro objeto de investigación, es decir, el texto museístico accesible del Museo Memoria de Andalucía. En la mayoría de los casos, como se verá más adelante, se trata de textos que se elaboraron partiendo directamente del expositivo, es decir, la obra de arte como TO, pues a menudo no van acompañados de una leyenda y no existe un texto previo creado para el público en general, por lo que podemos hablar de traducción multimodal accesible.

Al pasar la información transmitida por un TO -sea de contenido general o especializado- a LF, se cambia de variedad lingüística y no de idioma por lo que hablamos de traducción intralingüística (Jakobson 1959: 233; Siever 2010: 224; Bredel \& Maaß 2016: 182s.). También se trata de una traducción intersemiótica y multimodal dado que el TO no solamente se traduce a texto verbal, sino también a imágenes, símbolos, pictogramas, etc. En el caso de que los receptores no sean nativos de una lengua, además de interlingüística, sería una traducción intercultural (Maaß 2018: 279). 
Cuando se traducen textos de un campo de especialidad hacia la LF se trata de una forma clara de comunicación entre emisor experto y receptor lego (Maaß \& Rink 2018: 28): "Werden fachliche Texte in Leichte Sprache übersetzt, so handelt es sich um eine besonders ausgeprägte Form der ExpertenLaien-Kommunikation." A causa de la poca experiencia que suelen tener los receptores de textos en LF con géneros textuales escritos, estos receptores no tienen acceso a la comunicación especializada, y a menudo tampoco a la de carácter general, dado que no disponen del vocabulario escrito necesario para ello (Maaß \& Rink 2018: 30). Aunque las autoras se refieren a la recepción de textos médicos redactados en LF, las reflexiones se pueden aplicar perfectamente a textos de otros ámbitos de especialidad como por ejemplo la arquitectura o el arte escultórico, que, entre otros, nos ocuparon en el marco del proyecto CITRA. Suscribimos plenamente la afirmación de que los textos especializados no solamente tienen que ser simplificados, sino también provistos de informaciones de las que dispone el lector medio en relación con los conocimientos previos presupuestos:

Fachliche, hier medizinische, Texte in Leichter Sprache müssen folglich nicht nur sprachlich vereinfacht werden; sie müssen systematisch auch solche Wissensvoraussetzungen einführen, die bei durchschnittlichen Leser(inne)n als Vorwissen vorausgesetzt werden können. (Maaß \& Rink 2018: 30)

En cuanto al léxico en textos de LF, se recomienda que este se limite al vocabulario básico y que se evite el uso de sinónimos, lenguaje especializado y metáforas (Maaß, Rink \& Zehrer 2014: 64). En este sentido, se renuncia al uso de términos específicos y sustantivos en general a favor del uso de formas verbales, lo que, según la relevancia de la terminología para la comprensión del texto, en ocasiones obliga a añadir un glosario terminológico con definiciones del lenguaje especializado (Netzwerk Leichte Sprache 2013).

A continuación, nos basaremos en el autor más conocido en relación con la LF en lengua española y con más publicaciones en este ámbito, Óscar García Muñoz, y en concreto en dos de sus manuales sobre las pautas en LF (García Muñoz 2012 y 2014). Para saber si un texto en LF cumple su función, es decir, si transmite de forma adecuada la información necesaria y que, además, los receptores comprendan los mensajes incluidos en el texto, García Muñoz (2014: 47) insiste en la importancia y necesidad de realizar estudios de evaluación con grupos de lectores. Entre los resultados obtenidos 
con personas con discapacidad intelectual destaca la dificultad de reconocer sinónimos infrecuentes y palabras complejas. El autor resalta que "las palabras de los textos en LF deben ser sencillas, cortas, fáciles de pronunciar y de uso cotidiano para su reconocimiento inmediato" (García Muñoz 2014: 18). En el caso de vocabulario nuevo, este se debe explicar mediante diferentes estrategias de traducción como el uso de imágenes, contexto o una definición a modo de glosario en la misma página.

Igual que en las normas alemanas, se recomienda renunciar al uso de verbos nominalizados y mantener una misma denominación para un único concepto en vez de recurrir al uso de sinónimos. Otra característica de los textos científicos y técnicos en cuanto a la terminología son las abreviaturas, acrónimos y siglas, que se deben evitar, a menos que sean "muy conocidas o necesarias"; en este caso, se recomienda explicar su significado en la primera mención (García Muñoz 2014: 19). Igualmente se deben evitar la complejidad léxica, el uso de metáforas y abstracciones, así como la información irrelevante y los detalles superfluos:

Se deben evitar tecnicismos, jergas y palabras extranjeras. Si es necesario su uso, debe explicarse el significado a través de las estrategias antes mencionadas de inclusión de palabras nuevas. [...]Se debe ofrecer la información relevante y dar los detalles si son significativos y aportan información. Evitar detalles superfluos, decorativos, estilísticos o redundantes (García Muñoz 2014: 19-20).

\subsection{Pautas y criterios de redacción de textos en $A D$}

Debido a las numerosas categorías y subcategorías de museos (antropológicos, históricos, etnográficos, arqueológicos, de arquitectura, de artes decorativas, de artes visuales, de ciencias naturales, solo por citar algunos de los más conocidos) es común que la $\mathrm{AD}$ para visitantes con discapacidad visual de un determinado expositivo requiera el empleo de lenguajes especializados. En este sentido, el escollo más grande es la transmisión de la información técnica de la pieza. La amplia literatura existente sobre la redacción de textos técnicos y científicos (Widdowson 1979; Huckin \& Olsen 1991; Ciapuscio \& Kuguel 2002) concuerda en que usar únicamente una terminología técnica no basta para crear un puente de conocimiento en el caso de lectores no especialistas, pues la comunicación resultaría imposible. Entre las estrategias generales 
en el proceso de escritura técnica que facilitan la comprensión textual para lectores no especialistas se encuentran la explicitación -ya sea intercalando dichas explicaciones en el texto, o bien incluyendo ejemplos- o el empleo de analogías (Huckin \& Olsen 1991: 235) Aunque los estudios de estos autores no están enfocados hacia la $\mathrm{AD}$, sino únicamente hacia la redacción de textos científicos y técnicos, consideramos que se puede aplicar el mismo planteamiento a la redacción de una $\mathrm{AD}$. De hecho, al igual que ocurre en la escritura científico-técnica, en la que hay que contar con una diversidad de lectores, en el caso de la AD para museos y exposiciones de arte hay que identificar el tipo de audiencia antes de redactar el texto audiodescrito. Siguiendo la clasificación de Huckin \& Olsen, podemos diferenciar entre audiencia experta, no experta, internacional o multicultural y mixta (1991: 60-66).

La norma UNE 153020 de Audiodescripción para personas con discapacidad visual se publicó en España en 2005. Según formula la norma en el punto 2.1, la AD es "un sistema de apoyo a la comunicación que consiste en el conjunto de técnicas y habilidades aplicadas, con objeto de compensar la carencia de captación de la parte visual contenida en cualquier tipo de mensaje, suministrando una adecuada información sonora que la traduce o explica, de manera que el posible receptor discapacitado visual perciba dicho mensaje como un todo armónico y de la forma más parecida a como lo percibe una persona que ve" (AENOR 2005: 4). Las directrices proporcionan información sobre la situación espacial, paisajes, vestuario, gestos, miradas, emociones y actitudes de los personajes, etc., aportando los datos necesarios para que el acceso a la obra audiovisual sea lo más completo posible. Entre los requisitos más importantes recogidos en la norma UNE para crear un guion audiodescriptivo se observan los siguientes: uso de vocabulario adecuado, estilo de escritura fluido y sencillo, adjetivos concretos y terminología específica apropiada para cada película, aplicación de la regla espacio -temporal (cuándo, donde, quien, qué y cómo) y objetividad de la narración. Hay que evitar censurar o recortar excesos, describir lo que se desprende o deduce y adelantar sucesos (AENOR 2005).

Sin embargo, estas directrices se diseñaron para la AD fílmica, por lo que implican una narración muy sintética, que insiste en aquellos aspectos esenciales para comprender los personajes, el lugar en el que se desarrolla la acción y lo que sucede. Estas estrategias son aplicables a películas, series, 
teatro, documentales, pero se muestran insuficientes, o por lo menos incompletas, a la hora de audiodescribir museos, exposiciones de arte, monumentos o entornos naturales (patrimonio). Por ello, aunque la Norma UNE representa el punto de partida para establecer los requisitos básicos de calidad que debe cumplir nuestra AD, el procedimiento que se ha seguido para elaborar los textos audiodescritos de los objetos museísticos se sustenta en las pautas, criterios y directrices marcadas por los estudios sobre AD en museos, que permiten subsanar las deficiencias debidas al carácter impreciso e incompleto de la Norma misma.

Según las directrices de ABS (Salzhauer Axel et al. 2003), la AD de una obra de arte debe incluir aspectos generales como la información de la obra y su autor, la explicación de la forma, la técnica, el material empleado y la descripción de cromatismos, entre otros. Consideramos importante seguir la recomendación de incluir descripciones pormenorizadas (provide vivid details) de determinadas partes del objeto, contextualizándolo y añadiendo detalles y analogías (Giansante 2015) que favorezcan la comprensión de aquellos términos especialmente complejos. En palabras de Snyder, a diferencia de lo que ocurre en la AD fílmica, en la AD de una obra museística "we experiment with using more descriptive language" (2003: 197), debido a la necesidad de mantener la subjetividad y creatividad propia de cada obra de arte (Neves 2012: 279).

A continuación, pasamos a la comparación de la terminología utilizada en las dos modalidades de traducción, AD y LF, mediante una muestra de objetos museísticos pertenecientes al Museo Memoria de Andalucía y realizados dentro del proyecto CITRA.

\section{Estudio comparativo AD versus LF}

El estudio comparativo que se muestra a continuación se refiere al análisis de algunos fragmentos de AD y de LF de tres tipos de expositivos pertenecientes al campo de la arquitectura, la técnica del mosaico y la artesanía. Desde el punto de vista de la tipología textual, hemos optado por elegir objetos museísticos bi- y tridimensionales que presentan una organización secuencial discursiva que implica un grado de dificultad y abstracción creciente, empezando por expositivos de contenido semiespecializado para llegar a otros de contenido más complejo. 


\subsection{Objeto bidimensional}

El primer texto se ha extraído del panel llamado Línea del Tiempo que recorre toda la pared lateral de la Sala 4 y refleja, a través de una serie de imágenes y textos planos, la historia cultural y artística de Andalucía, desde la Prehistoria hasta la época contemporánea. Las imágenes o fotografías que acompañan cada texto son bidimensionales y por tanto carecen de profundidad o volumen. Se trata, pues, de textos sobre temas históricos, arquitectónicos y artísticos entre otros, por lo que incluyen vocabulario especializado y estructuras complejas, bien que, en la mayoría de los casos, enfocados hacia el lector no experto. El arte es un campo muy amplio que abarca la pintura, la escultura, el grabado, la arquitectura o las artes decorativas. Cada una de estas áreas cuenta con su propia terminología técnica, que puede llegar a convertirse en un verdadero desafío para el traductor.

En este caso, nos ocupamos del texto "Alfonso X ordena el comienzo de los trabajos en la iglesia de Santa Ana”, que pertenece al ámbito de la arquitectura, por lo que presenta una serie de dificultades de comprensión debido a tecnicismos propios del lenguaje especializado como por ejemplo bóvedas de crucería o arcos formeros (Tabla 1).

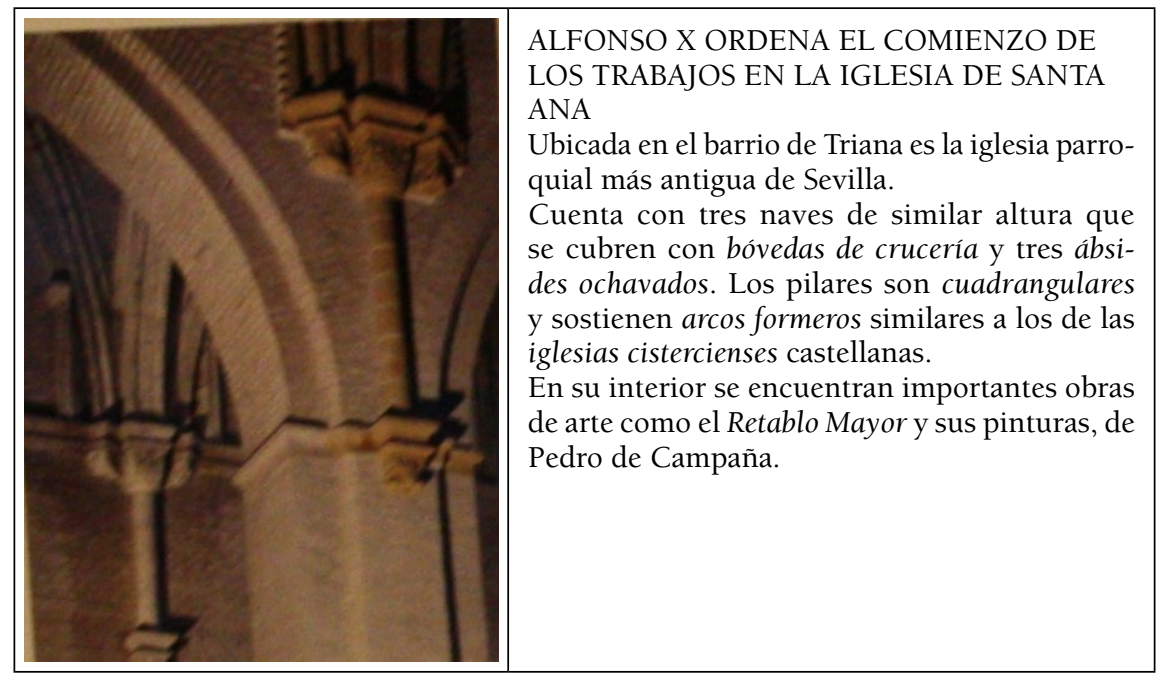

Tabla 1. Iglesia de Santa Ana. TO 
La tabla que aparece a continuación, muestra las traducciones intralingüísticas a LF y AD:

\begin{tabular}{|l|l|}
\hline \multicolumn{1}{|c|}{ TEXTO LF } & \multicolumn{1}{c|}{ TEXTO AD } \\
\hline ALFONSO X ORDENA EL COMIENZO & ALFONSO X ORDENA EL COMIENZO \\
DE LOS TRABAJOS EN LA IGLESIA DE & DE LOS TRABAJOS EN LA IGLESIA DE \\
SANTA ANA & SANTA ANA \\
Es la iglesia más antigua de Sevilla. Está & Esta iglesia empezó a construirse en el \\
en el barrio de Triana. La iglesia tiene tres & año 1266, por orden del rey Alfonso X. \\
naves de similar altura. Están cubiertas & Ubicada en el barrio de Triana, es la igle- \\
con bóvedas. Las bóvedas son techos con & sia parroquial más antigua de Sevilla. Su \\
forma curva. Los pilares tienen cuatro & interior cuenta con tres naves, cubiertas \\
ángulos. Los pilares aguantan arcos. & por bóvedas de crucería, también llama- \\
En el interior hay obras de arte muy & das bóvedas nervadas, características de \\
importantes. Por ejemplo, el Retablo & la arquitectura gótica, que están formadas \\
Mayor de Pedro de Campaña. El retablo & por la intersección de unos arcos, también \\
denominados nervios. Toda la iglesia se & realiza en ladrillo, el material propio de \\
es de madera. El retablo decora el altar. & la zona, menos los nervios de los arcos, \\
que son de piedra. & La foto ofrece una visión del interior que \\
permite observar un detalle de los arcos \\
formeros, de color arena, que van de pilar \\
a pilar, coincidiendo con los tramos de la \\
bóveda. \\
El Retablo Mayor es una magnífica obra \\
en madera que conserva una colección de \\
pinturas sobre tablas, obra de Pedro de \\
Campaña.
\end{tabular}

Tabla 2. Iglesia de Santa Ana. LF y AD

Este ejemplo de LF nos muestra cómo se pueden adaptar los textos a las necesidades de personas que tienen dificultades en la comprensión y aprendizaje de la lectura. Según García Muñoz (2012), se recomiendan frases cortas y concisas, lenguaje sencillo, una idea por cada frase, entre otras estrategias. En el TO aparecen sustantivos (bóvedas de crucería y ábsides) y adjetivos (ochavados y formeros), característicos del lenguaje especializado que dificultan la comprensión del texto por lo que se han eliminado en el texto en LF. Además, se ha simplificado la sintaxis, prescindiendo de las oraciones coordinadas y subordinadas, y se han reordenado los elementos de las oraciones, según el 
orden: sujeto, verbo y complementos. La función informativa y divulgativa del TO se mantiene en el TM, adaptándose, sin embargo, la complejidad terminológica y abstracción del texto según la situación comunicativa real, que varía en función del usuario del TM, es decir, sus necesidades concretas durante la visita al museo. Para resolver las dificultades terminológicas, marcadas en cursiva, se optó por las siguientes técnicas de traducción: Simplificación del término: bóvedas de crucería $\rightarrow$ bóvedas; arcos formeros $\rightarrow$ arcos; cuadrangulares $\rightarrow$ tienen cuatro ángulos; sostienen arcos $\rightarrow$ aguantan arcos. Omisión de términos: crucería; ábsides ochavados; formeros; iglesias cistercienses; Lauda Sepulcral de D. Iñigo López. Definición/explicitación del término: bóvedas son techos con forma curva; el retablo es de madera; el retablo decora el altar.

Pasando a analizar la AD de este texto artístico, consideramos necesario plantear una breve premisa. Insistiendo en las múltiples dificultades del lenguaje artístico, Carpi defiende que estos textos especializados "por ser el resultado de una traducción intersemiótica [...] y por mantener una estricta relación con objetos del mundo extralingüístico, pueden plantear relevantes problemas de traducción" (Carpi 2015: 13). En el caso del microtexto de arquitectura que se tuvo que audiodescribir, el apoyo de la imagen resultaba fundamental, tal y como se puede apreciar en la Tabla 1 . Si reivindicamos la importancia de la imagen y su valor semántico a la hora de entender términos técnicos como arcos formeros o bóveda de crucería, entendemos que la imposibilidad por parte del usuario con discapacidad visual de acceder a imágenes, diapositivas, fotos o cualquier otro recurso visual que ilustre el texto, dificulta enormemente la interpretación del mensaje. Así pues, fue necesario utilizar técnicas de traducción encaminadas a lograr la comprensión del texto por parte de usuarios invidentes; para explicar los términos arquitectónicos que se acaban de mencionar, fue necesario recurrir a dos estrategias de traducción: la amplificación, mediante la adición de nuevos términos, y la explicitación, tal y como se puede apreciar en la tabla 2. Directamente relacionada con ambas estrategias, en algunos casos se utilizó también la paráfrasis, entendida como amplificación o explicación del significado de un determinado sintagma. A diferencia de lo que ocurre en la redacción del texto en LF, para la AD en ningún momento se activaron técnicas de omisión (el término técnico ha de conservarse), ni tampoco de simplificación/reducción. 


\subsection{Objeto tridimensional con posibilidad de exploración háptica}

Una parte importante del Museo Memoria de Andalucía está dedicada a contenidos expositivos llamados estratos; el término tiene una doble explicación: define los diferentes estratos de la memoria e indica que los objetos expuestos presentan una disposición en estratos. En su mayoría se trata de réplicas de obras conocidas o significativas de cada momento histórico y pueden tocarse, incluso en ocasiones se puede interactuar con ellas (González Villajos 2010: 5). Como ya puso de manifiesto Snyder, "other senses, such as touch or hearing, enable description users to further construct highly detailed impressions of a work on display" (Snyder 2010: 58). Uno de estos objetos museísticos tridimensionales es nuestro siguiente ejemplo que, conjuntamente con una breve leyenda que se encuentra junto a la pieza, se convirtió en el TO de las traducciones a LF y AD.

Se pueden observar dos tipos de traducción que se llevan a cabo de forma simultanea: una traducción intralingüística que se refiere a la leyenda en español que acompaña el expositivo así como al TM, es decir, el texto en LF y AD; además, se trata de una traducción intersemiótica al transferir la información codificada en el expositivo a un texto en LF y una AD, a saber, la imagen, las dimensiones, la textura y los materiales, entre otros aspectos.

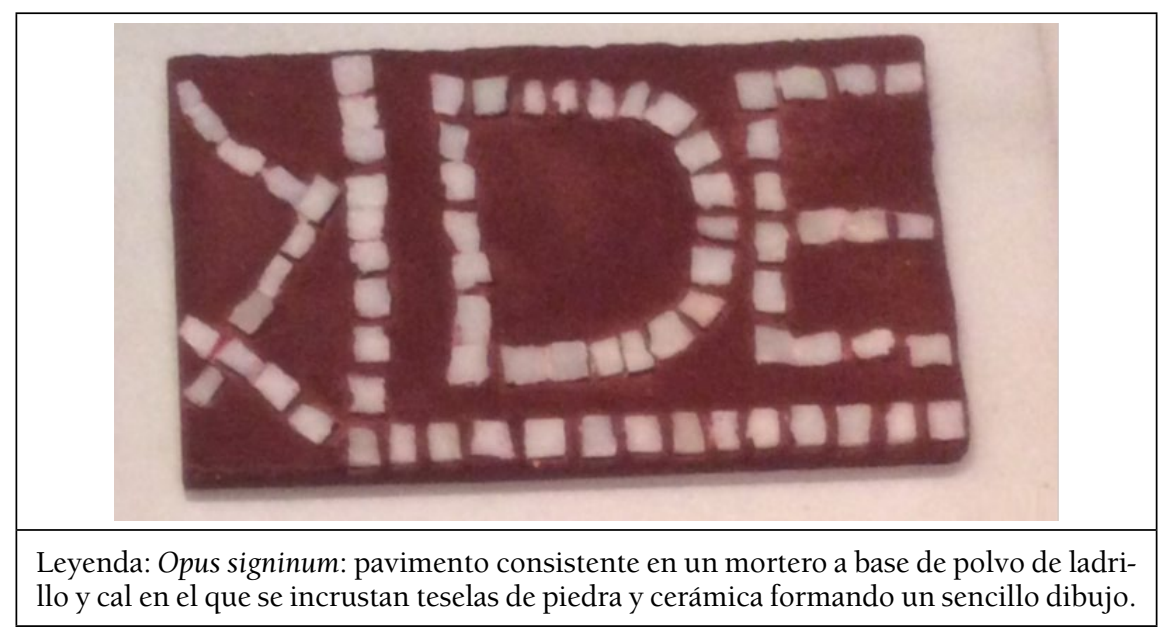

Tabla 3. Opus signinum. TO 


\begin{tabular}{|c|c|}
\hline TEXTO LF & TEXTO AD CON EXPLORACIÓN TÁCTIL \\
\hline $\begin{array}{l}\text { Opus signinum: pavimento } \\
\text { consistente en una mezcla } \\
\text { de polvo de ladrillo y cal. } \\
\text { La mezcla se llama mor- } \\
\text { tero. En este mortero se } \\
\text { colocan pequeñas piezas. } \\
\text { Las piezas tienen forma de } \\
\text { cubo y se llaman teselas. } \\
\text { Las teselas están hechas } \\
\text { de piedra y cerámica. Las } \\
\text { teselas se utilizan para } \\
\text { hacer un mosaico. En } \\
\text { este tipo de mosaico, las } \\
\text { teselas forman un sencillo } \\
\text { dibujo. }\end{array}$ & $\begin{array}{l}\text { Opus signinum: Desliza la mano hacia el último mosaico. } \\
\text { Este tipo de mosaico se conoce en latín por el nombre } \\
\text { Opus signinum, aunque realmente se trata del nombre } \\
\text { que se le daba a la técnica que se usaba para crear este } \\
\text { tipo de mosaicos. El fondo, de color rojo ladrillo, está } \\
\text { compuesto por mortero a base de cal, arena y fragmen- } \\
\text { tos de cerámica y resulta áspero al tacto. Este tipo de } \\
\text { mortero, por sus características impermeabilizantes, fue } \\
\text { muy utilizado como sistema de recubrimiento de suelos } \\
\text { y también muros, en piscinas, cisternas, canales, etc. Pero } \\
\text { fue principalmente en el interior de los edificios donde } \\
\text { esta técnica poco a poco se fue enriqueciendo mediante } \\
\text { la inclusión de pequeñas teselas de colores que dibujaban } \\
\text { motivos geométricos de carácter ornamental. Las teselas } \\
\text { son de mármol blanco, de forma cuadrada y dibujan lo } \\
\text { que parecen letras grandes en la superficie. Sitúa la mano } \\
\text { en el borde izquierdo del mosaico y desplázala hacia tu } \\
\text { derecha. De izquierda a derecha podrás tocar una letra } \\
\text { «» invertida, una «D» y una «E» mayúsculas. Estas últi- } \\
\text { mas dos letras parecen estar subrayadas con una línea de } \\
\text { teselas. Como puedes notar, las teselas están incrustadas } \\
\text { sobre la base del mosaico a diferentes alturas. }\end{array}$ \\
\hline
\end{tabular}

Tabla 4. Opus signinum. LF y AD

En el texto en LF, de nuevo observamos la simplificación de la sintaxis mediante la eliminación de las oraciones subordinadas, ofreciendo seis oraciones cortas y sencillas. Las dificultades terminológicas se resuelven recurriendo a la simplificación del término (mortero $\rightarrow$ mezcla; tesela $\rightarrow$ pieza; incrustar $\rightarrow$ colocar), la sinonimia/hiperonimia (mortero $\rightarrow$ mezcla; tesela $\rightarrow$ pequeña pieza; incrustar $\rightarrow$ colocar) y la definición/explicitación (mortero $\rightarrow$ mezcla de polvo de ladrillo y cal, la mezcla se llama mortero; teselas $\rightarrow$ pequeñas piezas, tienen forma de cubo, se llaman teselas, se utilizan para hacer un mosaico, las teselas forman un sencillo dibujo).

En relación con la AD de este objeto tridimensional, que permite el apoyo de la exploración táctil, la función de las unidades de información (Díaz Cintas 2010: 174) que se han introducido, así como las indicaciones para el recorrido táctil, ha sido doble: por un lado, ha aclarado aspectos de la pieza difíciles de entender para un invidente y, por otro, ha permitido contextualizar 
la técnica del mosaico, que alcanzaría su auge con los Romanos. No es de extrañar, por tanto, que la técnica de traducción más empleada sea la amplificación. En este sentido, creemos que la comprensión del contexto mediante la inserción de aclaraciones y descripciones no incluidas en el texto original (la pieza de mosaico) es fundamental, porque permite darle sentido al expositivo.

\subsection{Objeto tridimensional sin posibilidad de exploración háptica}

Por último, queremos analizar el discurso especializado en la AD de un TO especialmente complejo: nos referimos a una de las cuatro vitrinas de la Sala 4, titulada: El arte del lutier (figura 1). En este caso, la fase de documentación resultó extremadamente difícil, pues el expositivo solo disponía de un título

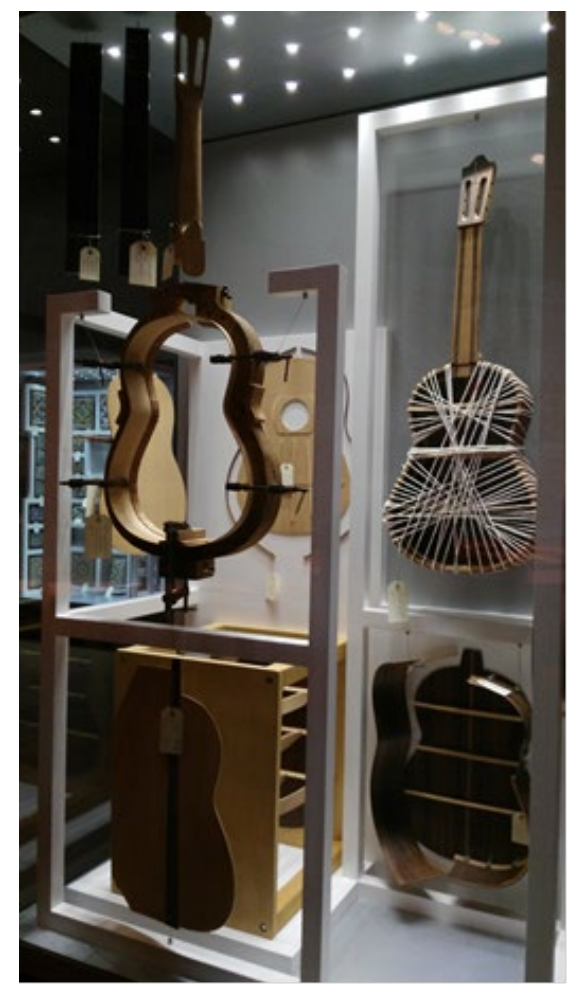

Figura 1. Vitrina El arte del lutier. TO 
genérico y fue necesaria la creación completa de un texto audiodescrito que expresara la materia, forma, función, relieve y disposición espacial de las distintas piezas que componían el objeto museístico. La vitrina conforma un prisma rectangular con unas dimensiones aproximadas de 3 metros de alto, 1,5 metros de ancho y un metro de fondo. Salvo un panel de color blanco que hace las veces de fondo, la vitrina está acristalada y permite visionar una serie de objetos relacionados con la construcción artesanal de una guitarra española. La construcción de una guitarra española prevé un complejo trabajo de artesanía que comprende la fabricación de cada uno de los componentes del instrumento. La vitrina recoge todas las fases de este proceso de construcción. Las distintas piezas de la guitarra, algunas de ellas suspendidas, así como los útiles para su construcción, ilustran el proceso de fabricación de este instrumento de artesanía desde el comienzo hasta el producto acabado. La imposibilidad de tocar las diferentes piezas dificulta mucho la elaboración de la $\mathrm{AD}$, pues cada elemento ocupa una determinada ubicación espacial dentro de la vitrina y se proyecta en forma de volumen, por lo que un visitante con discapacidad visual no puede observar el alto, el ancho, la profundidad y la perspectiva de cada elemento, características que hay que audiodescribir necesariamente.

Desde el punto de vista de la traducción accesible de este expositivo, fue necesaria una exhaustiva documentación técnica y fotográfica, para entender términos como pala, zoquete, mástil, tapa, aros, culata, cenezas, abanico, flancos, cadenas y centellones, solo por citar algunos términos, que constituyeron un verdadero reto a la hora de efectuar la traducción intersemiótica e intralingüística, así como la posterior traducción interlingüística de la AD. Teniendo en cuenta que en este caso había una dificultad añadida, pues, a diferencia del expositivo anterior, aquí era imposible realizar una exploración táctil que permitiera conocer las características de las piezas. Al no contar con un canal háptico que complementara el canal verbal de la $\mathrm{AD}$, las estrategias utilizadas en el proceso de escritura de la traducción intralingüística jugaron un papel fundamental a la hora de crear un texto audiodescrito del expositivo que fuera realmente accesible. En este sentido, como se puede observar en el fragmento siguiente, una de las técnicas de traducción que fue necesaria utilizar es la amplificación (Hurtado Albir 2001), mediante la 
introducción de aclaraciones y paráfrasis que permitiesen explicar el término y hacerlo comprensible para el usuario invidente. En palabras de la autora, la amplificación consiste en "introducir precisiones no formuladas en el texto original (informaciones, paráfrasis explicativas, etc.)" (ibid: 633). En el caso de palabras técnicas relacionadas con el trabajo artesano del lutier, en algunos casos se optó por introducir un equivalente funcional, empleando una palabra neutra y más comprensible, es decir, un hiperónimo, o bien un equivalente descriptivo, aspecto esencial de toda explicación. Es este el caso del término flancos, que se define como "láminas laterales de madera que dotan de volumen al cuerpo del instrumento".

VITRINA EL ARTE DEL LUTIER - FRAGMENTO DE AD

[...]Se trata de los flancos, unas láminas laterales de madera que dotan de volumen al cuerpo del instrumento. De unos $15 \mathrm{~mm}$ de grosor y unos $20 \mathrm{~cm}$ de ancho, están incrustadas en una moldura de madera de varios centímetros de grosor y gracias a ella obtienen la forma sinuosa por la que es famosa la guitarra española. Están fijadas a la moldura mediante varios sargentos de carpintero, unas abrazaderas de sujeción a forma de letra F mayúscula. La pieza central muestra un diapasón en proceso de elaboración, con los dos primeros trastes de metal ya acoplados. A la derecha, aparece un mástil, una pieza de unos $32 \mathrm{~cm}$ de largo que comienza en el centro superior de la caja de resonancia y termina en la cabeza, o parte superior de la guitarra, que ya está perforada para la instalación del clavijero, la pieza donde se colocan las clavijas que permiten apretar o aflojar las cuerdas [... S Suspendida a la misma altura en el lateral izquierdo de la vitrina se encuentra el anverso o frontal de la tapa armónica, el cuerpo de la guitarra. Se está incrustando el zuncho, un aro de unos $3 \mathrm{~cm}$ de grosor, con motivos geométricos en forma de corona circular, que rodea la boca de la guitarra. El fondo contiene las costillas, tres listones de madera posicionados en el interior, que refuerzan la estructura del cuerpo de la guitarra, dotando a la parte posterior de robustez.

Tabla 5. Vitrina El Arte del Lutier. AD 


\section{VITRINA EL ARTE DEL LUTIER - FRAGMENTO EN LF}

[...]Son las láminas laterales de la guitarra. Son de madera y dan volumen al instrumento. Las láminas están metidas en una moldura de madera. Esta moldura le da la forma curva a la guitarra española. Las láminas se sujetan con unas herramientas metálicas. En la pieza central se ve una tabla fina de madera. En esta tabla se pulsan las cuerdas para conseguir las diferentes notas. La tabla tiene dos finas tiras de metal. En estas tiras se debe apoyar el dedo para obtener una nota. A la derecha aparece una pieza de madera larga y estrecha. Al final hay una pieza con agujeros para poner las clavijas. Las clavijas funcionan como un tornillo. Sirven para mejorar el sonido de la guitarra. $[\ldots]$

Tabla 6. Vitrina El Arte del Lutier. LF

Las estrategias llevadas a cabo en los textos en LF de los ejemplos anteriores se repiten en este último; por un lado, se recurre a la simplificación de la sintaxis; por otro lado, se reduce el nivel de dificultad terminológica. Todo lo contrario ocurre en la $\mathrm{AD}$, donde los tecnicismos se mantienen, seguidos de una explicitación o aclaración en forma de glosa intratextual. Sin embargo, en el caso de los términos diapasón y traste, se abogó por recurrir a la traducción literal, conservando el término sin añadir más información, es decir, con "explicitación cero" (Herrezuelo Campos 2008: 170), pues los usuarios invidentes interpelados para el control de calidad de la AD afirmaron conocer ambos significados. En otras ocasiones, finalmente, se recurrió a una analogía que procede de la experiencia cotidiana, con el fin de facilitar la comprensión: es este el caso del sargento de carpintero, cuya forma se asocia a la letra $F$ mayúscula.

Como se puede observar en este último recurso accesible, cuando el expositivo no cuenta ni con leyenda ni con otro tipo de texto plano, el proceso de documentación conceptual y terminológica parte directa y exclusivamente de la obra museística. Dicha búsqueda exhaustiva de material facilitó la elaboración simultánea de la AD, con posterior traducción hacia la LF. En la tabla 7 se muestran los términos relacionados con este último expositivo, acompañados por las técnicas de traducción utilizadas, tanto en la elaboración de la AD como en la simplificación de la complejidad terminológica y sintáctica en LF. 


\begin{tabular}{|c|c|c|c|}
\hline $\begin{array}{l}\text { Técnica de } \\
\text { traducción }\end{array}$ & Término & $\mathrm{AD}$ & LF \\
\hline $\begin{array}{l}\text { AD: } \\
\text { amplificación, } \\
\text { explicitación } \\
\text { LC: } \\
\text { simplificación, } \\
\text { omisión, } \\
\text { definición }\end{array}$ & Flanco & $\begin{array}{l}\text { Se trata de los flancos, } \\
\text { unas láminas laterales } \\
\text { de madera que dotan } \\
\text { de volumen al cuerpo } \\
\text { del instrumento. De } \\
\text { unos } 15 \mathrm{~mm} \text { de grosor } \\
\text { y unos } 20 \mathrm{~cm} \text { de ancho, } \\
\text { están incrustados en } \\
\text { una moldura de madera } \\
\text { de varios centímetros } \\
\text { de grosor y gracias a } \\
\text { ella obtienen la forma } \\
\text { sinuosa por la que } \\
\text { es famosa la guitarra } \\
\text { española. }\end{array}$ & $\begin{array}{l}\text { Son las láminas } \\
\text { laterales de la guitarra. } \\
\text { Son de madera y } \\
\text { dan volumen al } \\
\text { instrumento. Las } \\
\text { láminas están metidas } \\
\text { en una moldura de } \\
\text { madera. Esta moldura } \\
\text { le da la forma curva a } \\
\text { la guitarra española. }\end{array}$ \\
\hline $\begin{array}{l}\text { AD: } \\
\text { amplificación, } \\
\text { explicitación, } \\
\text { definición } \\
\text { LF: } \\
\text { simplificación, } \\
\text { omisión, } \\
\text { hiperonimia }\end{array}$ & $\begin{array}{l}\text { sargentos } \\
\text { de } \\
\text { carpintero }\end{array}$ & $\begin{array}{l}\text { sargentos de carpintero, } \\
\text { unas abrazaderas de } \\
\text { sujeción en forma de } \\
\text { letra F mayúscula }\end{array}$ & herramientas metálicas \\
\hline $\begin{array}{l}\text { AD: trad. literal } \\
\text { (explicitación } \\
\text { cero) } \\
\text { LF: } \\
\text { simplificación, } \\
\text { omisión, } \\
\text { hiperonimia, } \\
\text { definición }\end{array}$ & Diapasón & diapasón & $\begin{array}{l}\text {...tabla fina de } \\
\text { madera. En esta tabla } \\
\text { se pulsan las cuerdas } \\
\text { para conseguir las } \\
\text { diferentes notas. La } \\
\text { tabla tiene dos finas } \\
\text { tiras de metal. }\end{array}$ \\
\hline $\begin{array}{l}\text { AD: trad. literal } \\
\text { (explicitación } \\
\text { cero) } \\
\text { LF: } \\
\text { simplificación, } \\
\text { omisión, } \\
\text { hiperonimia, } \\
\text { definición }\end{array}$ & Traste & traste & $\begin{array}{l}\text { La tabla tiene dos finas } \\
\text { tiras de metal. En estas } \\
\text { tiras se debe apoyar el } \\
\text { dedo para obtener una } \\
\text { nota. }\end{array}$ \\
\hline
\end{tabular}




\begin{tabular}{|c|c|c|c|}
\hline $\begin{array}{l}\text { AD: } \\
\text { amplificación, } \\
\text { explicitación } \\
\text { LC: } \\
\text { simplificación, } \\
\text { omisión, } \\
\text { hiperonimia, } \\
\text { definición }\end{array}$ & mástil & $\begin{array}{l}\text { A la derecha, aparece } \\
\text { un mástil, una pieza de } \\
\text { unos } 32 \mathrm{~cm} \text { de largo } \\
\text { que comienza en el } \\
\text { centro superior de la } \\
\text { caja de resonancia y } \\
\text { termina en la cabeza, } \\
\text { o parte superior de } \\
\text { la guitarra, que ya } \\
\text { está perforada para } \\
\text { la instalación del } \\
\text { clavijero. }\end{array}$ & $\begin{array}{l}\text { A la derecha aparece } \\
\text { una pieza de madera } \\
\text { larga y estrecha. Al } \\
\text { final de la pieza hay } \\
\text { agujeros para poner las } \\
\text { clavijas. }\end{array}$ \\
\hline $\begin{array}{l}\text { AD: } \\
\text { amplificación, } \\
\text { explicitación } \\
\text { LF: } \\
\text { simplificación, } \\
\text { omisión }\end{array}$ & cabeza & $\begin{array}{l}\text {..termina en la cabeza, } \\
\text { o parte superior de } \\
\text { la guitarra, que ya } \\
\text { está perforada para } \\
\text { la instalación del } \\
\text { clavijero. }\end{array}$ & final de la pieza \\
\hline $\begin{array}{l}\text { AD: } \\
\text { amplificación, } \\
\text { explicitación } \\
\text { LF: } \\
\text { simplificación, } \\
\text { omisión }\end{array}$ & clavijero & $\begin{array}{l}\text {...clavijero, la pieza } \\
\text { donde se colocan las } \\
\text { clavijas... }\end{array}$ & $\begin{array}{l}\text { hay una pieza con } \\
\text { agujeros }\end{array}$ \\
\hline $\begin{array}{l}\text { AD: } \\
\text { amplificación, } \\
\text { explicitación } \\
\text { LF: } \\
\text { simplificación, } \\
\text { hiperonimia, } \\
\text { definición }\end{array}$ & clavija & $\begin{array}{l}\text {...se colocan las } \\
\text { clavijas que permiten } \\
\text { apretar o aflojar las } \\
\text { cuerdas. }\end{array}$ & $\begin{array}{l}\text { Las clavijas funcionan } \\
\text { como un tornillo. } \\
\text { Sirven para mejorar el } \\
\text { sonido de la guitarra. }\end{array}$ \\
\hline $\begin{array}{l}\text { AD: } \\
\text { amplificación, } \\
\text { explicitación } \\
\text { LF: } \\
\text { simplificación, } \\
\text { omisión, } \\
\text { hiperonimia }\end{array}$ & zuncho & $\begin{array}{l}\text { Se está incrustando el } \\
\text { zuncho, un aro de unos } \\
3 \mathrm{~cm} \text { de grosor, con } \\
\text { motivos geométricos } \\
\text { en forma de corona } \\
\text { circular, que rodea la } \\
\text { boca de la guitarra. }\end{array}$ & $\begin{array}{l}\text { aro que rodea el hueco } \\
\text { de la guitarra }\end{array}$ \\
\hline
\end{tabular}




\begin{tabular}{|c|c|c|c|}
\hline $\begin{array}{l}\text { AD: } \\
\text { amplificación, } \\
\text { explicitación } \\
\text { LF: } \\
\text { simplificación, } \\
\text { omisión, } \\
\text { hiperonimia }\end{array}$ & costillas & $\begin{array}{l}\text { El fondo contiene las } \\
\text { costillas, tres listones de } \\
\text { madera posicionados } \\
\text { en el interior de la } \\
\text { guitarra que refuerzan } \\
\text { la estructura del cuerpo } \\
\text { de la guitarra, dotando } \\
\text { a la parte posterior de } \\
\text { robustez. }\end{array}$ & $\begin{array}{l}\text { En el fondo hay tres } \\
\text { varitas de madera. Con } \\
\text { las varitas, la guitarra } \\
\text { es más robusta. }\end{array}$ \\
\hline
\end{tabular}

Tabla 7. Vitrina El arte del Lutier. Técnicas de traducción en AD y LF.

La tabla muestra una diferencia relevante entre las estrategias utilizadas en ambos procesos de traducción. Por lo general, en relación con la LF, las técnicas prioritarias son la simplificación, la hiperonimia y la omisión. Por lo contrario, en la AD aparecen con más frecuencia la amplificación y la explicitación.

\section{Conclusiones}

En este estudio hemos analizado las estrategias de traducción más comunes adoptadas en la elaboración de la AD y la LF de algunos objetos museísticos. Hemos demostrado que dichas técnicas varían en relación con el género de expositivo y el tipo de traducción accesible demandada. En este sentido, se activan determinados procesos de traducción de acuerdo con los diferentes grados de especialidad y abstracción y, por tanto, dificultad terminológica que presente cada uno de los ejemplos analizados. No solamente los expositivos en tanto que TO, sino también los textos meta están enfocados hacia un público la mayoría de las veces no experto. Los usuarios legos, que a su vez son los receptores de los recursos accesibles, determinan la variedad lingüística del texto objeto de traducción: la AD y el texto en LF. En ambas modalidades de traducción, se observa la adaptación del grado de abstracción y dificultad terminológica al receptor del TM, sobre todo en el expositivo que presenta una mayor complejidad sintáctica, semántica y terminológica: la Vitrina del Lutier.

En el caso de la LF, se simplificaron tanto las estructuras oracionales como la complejidad terminológica, activándose sobre todo las estrategias de 
simplificación, hiperonimia y omisión. En la AD se aplicaron principalmente la amplificación y explicitación mediante perífrasis para explicar un término que carece de transparencia para el destinatario. Los casos de hipertraducción, con fuerte incremento de los detalles, se justifican con la necesidad de satisfacer las preferencias y expectativas de los usuarios ciegos, que piden una mayor información narrativa y descriptiva de las imágenes.

Sin embargo, somos conscientes de que definir las necesidades de los usuarios con discapacidad sensorial o cognitiva es bastante complicado, puesto que son grupos extremadamente heterogéneos, tratándose de colectivos con diferentes tipos de discapacidad, edad, nivel cultural e intereses, como hemos tenido ocasión de observar a lo largo de este estudio. Además, se ha podido demostrar que en el caso de estas modalidades de traducción accesible intralingüística (AD y LF), dependiendo del grado de dificultad terminológica del texto, los traductores se enfrentan a una ardua labor de búsqueda de documentación que a menudo puede conllevar una dedicación excesiva en cuanto al tiempo invertido (Schum 2017). En todo caso, los estudios de recepción (Braun 2008; Jiménez et al. 2010; Soler 2012) representan el único y verdadero control de calidad, pues, la verdadera accesibilidad consiste en ponerse en el lugar del otro, diseñar y adaptar pensando en todas las personas. Solo poniéndose en la piel de cada uno de los colectivos con algún tipo de discapacidad se conseguirá diseñar un plan de accesibilidad integral que incluya unos indicadores de calidad basados en el análisis de las estrategias de traducción y los ítems más recurrentes (estructura gramatical de las oraciones, subjetividad u objetividad, presencia o ausencia de juicios de valor, etc.). Asimismo, hacemos hincapié en la necesidad de futuros estudios de recepción que midan la eficacia de los recursos accesibles y el grado de satisfacción del receptor, permitiéndonos avanzar en el campo de la accesibilidad museística. 


\section{Referencias bibliográficas}

AENOR. (2005) Norma UNE: 153020. Audiodescripción para personas con discapacidad visual. Requisitos para la audiodescripción y elaboración de audioguías. Madrid: AENOR.

Aragall i Clavé, Francesc; Inma Bonet; Antonio Espinosa Ruiz \& Carmina Bonmartí Lledó. (2013) "Conceptos básicos sobre discapacidad, diversidad humana y diseño para todos aplicados a la museología." En: Espinosa Ruiz, Antonio \& Carmina Bonmartí (eds.) 2013. Manual de accesibilidad e inclusión en museos y lugares del patrimonio cultural y natural. Gijón: Ediciones Trea, pp. 25-39.

BRAUN, Sabine. (2008) "Audiodescription research: state of the art and beyond". Translation Studies in the New Millenium, 6, pp. 14-30.

BARnes, Colin \& Geof Mercer. (2010) Exploring Disability. Cambridge: Polity Press.

BOE. (1987) Real Decreto 620/1987, de 10 de abril, por el que se aprueba el Reglamento de Museos de Titularidad Estatal y del Sistema Español de Museos. Madrid: Boletín Oficial del Estado, 114, de 13 de mayo de 1987.

Bredel, Ursula \& Christiane Maaß. (2016) Leichte Sprache. Theoretische Grundlagen. Orientierung für die Praxis. Berlin: Dudenverlag.

CReAcCesible S. L. (2012) Directrices para Materiales de Lectura Fácil. Madrid: Creaccesible S. L.

CARLUCCI, Laura. (2018) "Prácticas cooperativas de escritura en el diseño de recursos museísticos accesibles." En: Arroyo González, Rosario; Mariano G. Fernández Almenara; Christina Holgado-Saez \& Teresa Lara Moreno (eds.) 2018. Investigación en la escritura: tecnología, afectividad y competencia académico-cultural. Barcelona: Editorial Octaedro, pp. 159-166.

CARPI, Elena. (2015) "El español de la pintura y los recursos lexicográficos y terminológicos: cómo traducir al español tempera y guazzo." Cuadernos AISPI 6, pp. 111-126.

CiAPUSCIO, Guiomar \& Inés Kuguel. (2002) "Hacia una tipología del discurso especializado: aspectos teóricos y aplicados.” En: García Palacios, Joaquín \& María Teresa Fuentes Morán (eds.) 2002. Texto, terminología y traducción. Salamanca: Ediciones Galmar, pp. 37-74.

Coll, César; Elena Martín; Teresa Mauri; Mariana Miras; Javier Ornubia; Isabel Solé \& Antoni Zabala. (2007) El constructivismo en el aula. Barcelona: Graó. 
DíAZ CINTAS, Jorge. (2010) "La accesibilidad a los medios de comunicación audiovisual a través del subtitulado y de la audiodescripción." En: González, Luis \& Pollux Hernúñez (eds.) 2010. El español, lengua de traducción para la cooperación y el diálogo. Madrid: Instituto Cervantes, pp.157-180.

FlóREZ CRESPO, María del Mar. (2006) "La museología crítica y los estudios de público en los museos de arte contemporáneo: caso del museo de arte contemporáneo de Castilla y León, MUSAC." De Arte 5, pp. 231-243.

FLUCK, Hans-Rüdiger. (1996 [1976]) Fachsprachen: Einführung und Bibliographie. (UTB 483) 5., überarb. u. erw. Aufl. Tübingen: Francke.

FREYHOFF, Geert et al. (1998) El camino más fácil: directrices europeas para generar información de fácil lectura. Bruselas: ILSMH European Association.

GARCíA MuÑOZ, Óscar. (2012) Lectura fácil: métodos de redacción y evaluación. Madrid: Real Patronato sobre Discapacidad.

GARCíA MuÑoz, Óscar. (2014) Lectura Fácil. Colección Guías prácticas de orientaciones para la inclusión educativa. Ministerio de Educación, Cultura y Deporte. Versión electrónica: <https://dilofacil.files.wordpress.com/2015/06/ libro-final.pdf>

Giansante, Lou. (2015) Writing verbal description audio tours. Versión electrónica: <http://www.lougiansante.org/p/writing-verbal-description-audio-tours. html>

GonZález Villajos, Santiago. (2010) Análisis crítico de contenidos en el Museo Memoria deAndalucía - Centro Cultural CajaGRANADA. Granada: Universidad. HEIDRICH, Franziska. (2016) Kommunikationsoptimierung im Fachübersetzungsprozess. Berlin: Frank \& Timme

Hernández Hernández, Francisca. (2011) "Museos, multiculturalidad e inclusión social." En: II Seminario de Investigación en Museología de los Países de Lengua Portuguesa y Española sobre El Pensamiento Museológico Contemporáneo. Buenos Aires: ICOFOM, pp. 407-417.

Herrezuelo Campos, María Inmaculada. (2008) "Estudio de la explicitación en dos publicaciones periódicas gratuitas bilingües (Ronda Iberia y Sur in English1). Análisis de casos." TRANS 12, pp. 169-188.

HuCKIN, Thomas N. \& Leslie A. Olsen. (1991) Technical Writing and Profesional Communication for Nonnative Speakers of English. New York: McGraw-Hill. Hurtado Albir, Amparo. (2001) Traducción y Traductología: Introducción a la traductología. Madrid: Cátedra. 
International Council Of Museums. (2017) Consejo Internacional de Museos. (ICOM) Estatutos: Versión electrónica: <https://icom.museum/wp-content/ uploads/2018/07/2017_ICOM_Statutes_SP_01.pdf>

JAKOBSON, Roman. (1959) "On linguistic aspects of translation." En: Reuben A. Brower (ed.) On translation. Cambridge: Harvard University Press, pp. 232-239.

JimÉnEZ, Catalina; Ana Rodríguez \& Claudia Seibel (eds.). (2010) Un Corpus de Cine. Fundamentos teóricos y aplicados de la audiodescripción. Granada: Ediciones Tragacanto.

Kiraly, Don. (2000) A Social Constructivist Approach to Translator Education; Empowerment from Theory to Practice. Manchester \& Northampton: St. Jerome Publishing.

Lorente Lorente, Jesús Pedro \& David Almazán Tomás. (2003) Museologia crítica y arte contemporáneo. Zaragoza: Prensas Universitarias de Zaragoza.

MAAß, Christiane. (2018) "Übersetzen in Leichte Sprache." En: Maaß, Christiane \& Isabel Rink (eds.) 2018. Handbuch Barrierefreie Kommunikation. Berlin: Frank \& Timme, pp. 273-302. Versión electrónica: <https://www.uni-hildesheim.de/media/fb3/uebersetzungswissenschaft/Leichte_Sprache_Seite/ Leichte_Sprache_Allgemein/978-3-7329-0407-5_Maass_UEbersetzen_in_ Leichte_Sprache.pdf>

MAAß, Christiane \& Isabel Rink. (2018) "Das nennt Ihr Arzt: Rigor. Medizinische Fachtexte in Leichter Sprache im Lichte des Ansatzes der Situated Translation." En: Jekat, Susanne; Martin Kappus \& Klaus Schubert (eds.) 2018. Barrieren abbauen, Sprache gestalten. Winterthur: ZHAW Zürcher Hochschule für Angewandte Wissenschaften (Working Papers in Applied Linguistics 14), pp. 4-38.

MAAß, Christiane; Isabel Rink \& Christiane Zehrer. (2014) "Leichte Sprache in der Sprach- und Übersetzungswissenschaft." En: Jekat, Susanne; Heike Jüngst; Klaus Schubert \& Claudia Villiger (eds.) 2014. Sprache barrierefrei gestalten: Perspektiven aus der Angewandten Linguistik. Berlin: Frank \& Timme. Versión electrónica: <https://www.uni-hildesheim.de/media/fb3/ uebersetzungswissenschaft/Leichte_Sprache_Seite/Publikationen/Leichte_ Sprache_in_der_Sprach-_und_\%C3\%9Cbersetzungswissenschaft.pdf>

NEVES, Josélia. (2012) "A multi-sensory approaches to (audio) describing visual art.” Multidisciplinarity in Audiovisual Translation. MonTI 4, pp. 277-293. 
NetzWerk Leichte Sprache. (2013) Die Regeln für Leichte Sprache. Versión electrónica: <https://www.leichte-sprache.org/wp-content/uploads/2017/11/ Regeln_Leichte_Sprache.pdf>

RODRÍGUEZ-TAPIA, Sergio. (2016) "Los textos especializados, semiespecializados y divulgativos: Una propuesta de análisis cualitativo y de clasificación cuantitativa." Signa: Revista de la Asociación Española de Semiótica 25, pp. 987-1006. RoElCKE, Thorsten. (1999) Fachsprachen. (Grundlagen der Germanistik 37 ) 3. Aufl. 2010. Berlin: Schmidt.

SALZHAUER AXEL, Elisabeth et al. (2003) "AEB's Guidelines for Verbal Description." En: Salzhauer, Elisabeth \& Nina Sobol (eds.) 2003. Art beyond sight: a resource guide to art, creativity, and visual impairment. Nueva York: AFB Press, pp. 229-237.

Schum, Swenja. (2017) "Barrierefreiheit als Herausforderung in der Fachtextübersetzung." En: Heidrich, Franziska (ed.) 2107. Fachkommunikation - die wissenschaftliche Sicht. Themenheft trans-kom 10:3, pp. 349-363. <http://www.trans-kom.eu/bd10nr03/trans-kom_10_03_05_Schum_ Barrierefrei.20171221.pdf>

SIEVER, Holger. (2010) Übersetzen und Interpretation. Die Herausbildung der Übersetzungswissenschaft als eigenständige wissenschaftliche Disziplin im deutschen Sprachraum von 1960 bis 2000. Frankfurt am Main: Lang.

SNYDER, Joel. (2003) "Verbal description: The visual made verbal." En: Salzhauer, Elisabeth \& Nina Sobol (eds.) 2003. Art beyond sight: a resource guide to art, creativity, and visual impairment. Nueva York: AFB Press, pp. 190-198.

SNYDER, Joel. (2010) Audio description guidelines and best practices. American Council of the Blind's Audio Description Project. Versión electrónica: http:// www.acb.org/adp/docs/AD-ACB-ADP\%20Guidelines\%203.1.doc

SOler Gallego, Silvia. (2012) Traducción y accesibilidad en el museo del siglo XXI. Granada: Ediciones Tragacanto.

StOlzE, Radegundis. (1999) Die Fachübersetzung. Eine Einführung. Tübingen: Narr.

WidDOWson, Henry G. (1979) Explorations in Applied Linguistics. Oxford: Oxford University Press. 


\section{BIONOTAS / BIONOTES}

LAURA CARlucci es profesora de Traducción en Ciencia y Tecnología y Traducción en Ciencias Sociales y Jurídicas español-italiano en la Facultad de Traducción e Interpretación de la Universidad de Granada. Imparte docencia en el Máster Universitario de Traducción Profesional en la Especialidad: Traducción Audiovisual y Accesibilidad. Entre sus líneas de investigación destacan la traducción audiovisual accesible, la traducción literaria, la didáctica de la traducción y la lexicografía ítalo-española. Ha participado en varios proyectos de investigación nacionales e internacionales relacionados con la accesibilidad. Es miembro del grupo TRACCE (Traducción y Accesibilidad). Desde 2006 es miembro del Consejo de Redacción de la revista Sendebar.

LAURA CARLUCCI is a Senior Lecturer in Italian Specialized Translation at the Department of Translation and Interpreting, and she teaches Audiovisual Translation and Accessibility in the Master of Professional Translation. Her research interests include accessible translation, literary and specialized translation, translation didactics and lexicology. She has participated in several national and international research projects related to accessibility. She is a member of the TRACCE (Translation and Accessibility) research team. Since 2006, she is a member of the Editorial Board of the journal Sendebar.

Claudia SEIBEL es profesora titular de la Facultad de Traducción e Interpretación de la Universidad de Granada. Entre sus líneas de investigación se encuentran la traducción audiovisual accesible, la didáctica de la traducción general y científico-técnica, así como la terminología aplicada a la traducción. Es miembro del grupo de investigación TRACCE (Traducción y Accesibilidad). Participa en el proyecto de investigación OPERA (Acceso al ocio y la cultura. Plataforma de difusión y evaluación de recursos audiovisuales accesibles).

Claudia SeIBel is senior lecturer at the Department of Translation and Interpreting of the University of Granada and member of the research and development team TRACCE (Translation and Accessibility), which aims to promote accessibility to culture for all. Her main research interests lie in the 
field of accessible translation, especially in easy reading and audio-description, and specialized translation. She is researcher of the OPERA project (Access to leisure and culture. Dissemination and assessment of audio visual accessible resources). 